\title{
Excitation-emission properties of $\mathrm{Er}^{3+}$ ions doped in nonlinear optical $\mathrm{TeO}_{2}-\mathrm{Nb}_{2} \mathrm{O}_{5}-\mathrm{ZnO}$ glass by $800 \mathrm{~nm}$ femtosecond laser excitation
}

\author{
Tomokatsu HAYAKAWA, ${ }^{\dagger}$ Masahiko HAYAKAWA and Masayuki NOGAMI \\ Ceramics Division, Materials Science and Engineering, Nagoya Institute of Technology, Gokiso, Showa-ku, Nagoya 466-8555
}

By excitation with $800 \mathrm{~nm}$ femtosecond laser, we observed the green up-conversion fluorescence at $\left.526 \mathrm{~nm}^{(2} \mathrm{H}_{11 / 2}{ }^{4} \mathrm{I}_{15 / 2}\right)$ and $548 \mathrm{~nm}\left({ }^{4} \mathrm{~S}_{3 / 2}-{ }^{4} \mathrm{I}_{15 / 2}\right)$ for $\mathrm{Er}^{3+}$ ions doped in $76 \mathrm{TeO}_{2} \cdot{ }^{20 \mathrm{Nb}_{2}} \mathrm{O}_{5} \cdot 4 \mathrm{ZnO}$ glass. From $I_{\mathrm{H}, \mathrm{S}} \sim P^{n}$ relationship $\left(I_{\mathrm{H}, \mathrm{S}}\right.$; fluorescence intensity of ${ }^{2} \mathrm{H}_{11 / 2}-{ }^{4} \mathbf{I}_{15 / 2}$ and ${ }^{4} S_{3 / 2}-{ }^{4} \mathbf{I}_{15 / 2}, P$ : laser power density, $n$ : the number of photons absorbed per visible photon emitted), the $n$ values of 1.4 and 1.3 were obtained at room temperature for $I_{H}$ and $I_{S}$, respectively, and approached "2" at lower temperatures and at lower excitation power densities. This indicates that two photons were involved in the excitation of the up-conversion fluorescence. Considering the up-conversion intensity at various repetition frequencies on fs laser excitation and the emission decay behaviors as well as the results of Judd-Ofelt analysis, we could explain this excitation mechanism in terms of energy transfer $\left(E T:{ }^{4} \mathbf{I}_{11 / 2}+{ }^{4} \mathbf{I}_{11 / 2} \rightarrow{ }^{4} \mathbf{F}_{7 / 2}+{ }^{4} \mathbf{I}_{15 / 2}\right.$, and $\left.{ }^{4} \mathbf{I}_{9 / 2}+{ }^{4} \mathbf{I}_{9 / 2} \rightarrow{ }^{4} \mathbf{S}_{3 / 2}+{ }^{4} \mathbf{I}_{13 / 2}\right)$. We shall also discuss on a back transfer process of the latter $E T$ for the reduction of the $n$ value at room temperature.

(2008 The Ceramic Society of Japan. All rights reserved.

Key-words : Fs laser heating, Er ${ }^{3+}$, GREEN up-conversion, Optical sensor, Excitation-emission mechanism, Tellurite glasses, JuddOfelt analysis

[Received June 11, 2008; Accepted September 11, 2008]

\section{Introduction}

A family of tellurite glasses is promising as a host material for rare-earth doping because of a low phonon energy of tellurite glasses $\left(600-700 \mathrm{~cm}^{-1}\right)$. And it is known that $\mathrm{Nb}_{2} \mathrm{O}_{5}$ and $\mathrm{ZnO}$ can improve vitrification, chemical duability and optical nonlinearity of tellurite glasses. ${ }^{1)} \mathrm{TeO}_{2}-\mathrm{Nb}_{2} \mathrm{O}_{5}-\mathrm{ZnO}$ glass we selected for rare-earth doping is one of recently developed tellurite-based glass systems and is interesting for nonlinear optical material of third order $\chi^{(3)}$ as well. ${ }^{2)-4)}$ We have investigated the optical properties of $\mathrm{Er}^{3+}$-doped $\mathrm{TeO}_{2}-\mathrm{Nb}_{2} \mathrm{O}_{5}-\mathrm{ZnO}$ glasses excited by femtosecond (fs) laser irradiation at $800 \mathrm{~nm}^{2)}$ When the nearinfrared (NIR) fs laser was irradiated to $\mathrm{Er}^{3+}$-doped $\mathrm{TeO}_{2}$-based glasses, green up-conversion fluorescence of $\mathrm{Er}^{3+}$ from ${ }^{2} \mathrm{H}_{11 / 2}$ and ${ }^{4} \mathrm{~S}_{3 / 2}$ levels was observed. From the fluorescence analysis, it was found that the green up-conversion fluorescence could simultaneously monitor a fs laser heating of $\mathrm{TeO}_{2}$-based glass matrix, which had large nonlinear absorption properties, owing to an imaginary part of $\chi^{(3)}\left(\operatorname{Im} \chi^{(3)}\right)$ and a lower thermal conductivity. This technique is very useful for the detection of laser spot temperature in $800 \mathrm{~nm}$ femtosecond laser manupulation. ${ }^{3)}$ However, we did not still address excitation-emission mechanism of the green up-conversion fluorescence under femtosecond laser excitation. In this paper, we discuss on it with fluorescence decay data and Judd-Ofelt analysis.

\section{Experimentals}

The $\mathrm{TeO}_{2}$-based glass sample was prepared using commercially-available chemicals $\mathrm{TeO}_{2}(<99.99 \%$, Kojundo Chemical Lab. Co., Ltd.), $\mathrm{Nb}_{2} \mathrm{O}_{5}, \mathrm{ZnO}$ and $\mathrm{Er}_{2} \mathrm{O}_{3}$ (Shin-Etsu Chemical Co.,

\footnotetext{
Corresponding author: T. Hayakawa; E-mail: hayatomo@ nitech. ac.jp
}

Ltd.). The composition was $76 \mathrm{TeO}_{2} \cdot 20 \mathrm{Nb}_{2} \mathrm{O}_{5} \cdot 4 \mathrm{ZnO}$ doped with 1.5 mass $\% \mathrm{Er}_{2} \mathrm{O}_{3}$. The powder was weighed precisely, mixed thoroughly, and melted in alumina crucible at $900^{\circ} \mathrm{C}$ for $30 \mathrm{~min}$ in air. The melt was poured onto a carbon mold, annealed at $400^{\circ} \mathrm{C}$ for $4 \mathrm{~h}$, and then cooled down to the room temperature. Each of its planar surfaces was polished to optical-flat for the optical measurements. The femtosecond pulse laser from a regenerative Ti: Sapphire laser system (Spectra Physics, Harricane) operating at a wavelength of $800 \mathrm{~nm}$ (spectral width: $~ 200$ $\mathrm{nm}$ ) with a $1 \mathrm{kHz}$ repetition rate and approximately 170 fs pulse duration was focused on this sample through an objective lens of $\times 20$ magnification $(\mathrm{NA}=0.45)$. The focal point was positioned just below the top surface (inside the glass investigated). The repetitional frequency of fs laser was changed down by an optical chopper (New Focus, Model 3501). The gate width for the fluorescence detection was controlled in an image-intensified chargecoupled device (ICCD) system (Oriel Instruments, InstaSpec ${ }^{\mathrm{TM}}$ V \& DG535) equipped with a monochromator (Jobin Yvon, HR320), and the fluorescence spectra were measured by different power densities of fs laser. The experimental condition for gating and delaying control is $200 \mathrm{~ns}$ and $300 \mu \mathrm{s}$, respectively.

For comparison, $\mathrm{Er}^{3+}$-doped aluminosilicate glass $\left(20 \mathrm{Al}_{2} \mathrm{O}_{3}\right.$. $80 \mathrm{SiO}_{2}$ doped with 10 mass $\% \mathrm{Er}_{2} \mathrm{O}_{3}$ ) was also prepared. In this study, we have aimed to estimate optical properties of $\mathrm{Er}^{3+}$ doped into $\mathrm{TeO}_{2} \cdot \mathrm{Nb}_{2} \mathrm{O}_{5} \cdot \mathrm{ZnO}$ glass system recently developed, which has a high third-order nonlinear optical susceptibility with $76 \mathrm{TeO}_{2} \cdot 20 \mathrm{Nb}_{2} \mathrm{O}_{5} \cdot 4 \mathrm{ZnO}$ composition as Lin et al. reported. ${ }^{4)}$ From the view of glass chemistry, $\mathrm{Er}^{3+}$ ions are expected to be clustered and to be neighbored each other via oxygen because of no network modifier oxide such as alkali- or alkaline-oxide. On the other hand, it is expected that $\mathrm{Nb}_{2} \mathrm{O}_{5}$ and $\mathrm{ZnO}$ act as intermediate oxide in tellurite glass network. To have good dispersivity of $\mathrm{Er}^{3+}$ ions in glass network, chemically stable 
aluminosilicate $^{5)}$ is a typical choice as reference of host glass on the femto-second laser irradiation. However, in aluminosilicate system, it is suspected to have a large multi-phonon relaxation rate of the emitting levels and consequently a weak luminescence intensity of $\mathrm{Er}^{3+}$ ions. Thus, we prepared a reference of an aluminosilicate glass in which 10 mass $\% \mathrm{Er}_{2} \mathrm{O}_{3}$ was doped with.

\section{Results and discussion}

We observed two green fluorescence lines of ${ }^{2} \mathrm{H}_{11 / 2}-{ }^{4} \mathrm{I}_{15 / 2}$ at $526 \mathrm{~nm}$ and ${ }^{4} \mathrm{~S}_{3 / 2}-{ }^{4} \mathrm{I}_{15 / 2}$ at $548 \mathrm{~nm}$ for $\mathrm{Er}^{3+}$ ions excited by $800 \mathrm{~nm}$ femtosecond laser. The intensities of these green up-conversion flurescence for incresing incident power density was obeyed by the relationship of $I_{\mathrm{H}, \mathrm{S}}=P^{n}$ ( $n$ : the number of photons excited for up-conversion fluorescence) and eventually the value of $n$ was 1.4 and 1.3 at room temperaure for ${ }^{2} \mathrm{H}_{11 / 2}$ and ${ }^{4} \mathrm{~S}_{3 / 2}$ fluorescences, respectively. To use lower laser power densities in comparison with fs laser excitation (several hundred $\mathrm{TW} / \mathrm{cm}^{2}$ ), a continuous-wave (cw) $800 \mathrm{~nm}$ semiconductor laser was installed to excite $\mathrm{Er}^{3+}$ ions in $\mathrm{TeO}_{2}-\mathrm{Nb}_{2} \mathrm{O}_{5}-\mathrm{ZnO}$ glass, which has several handred $\mathrm{mW}$ power (several tens $\mathrm{MW} / \mathrm{cm}^{2}$ ). In the same way as the case in femtosecond laser excitation, two lines of up-conversion fluorescence from ${ }^{2} \mathrm{H}_{11 / 2}$ and ${ }^{4} \mathrm{~S}_{3 / 2}$ levels (see Fig. 1) were observed. The $\log -\log$ plot of $I$ and $P$ elucidated that the value of $n$ was $\sim 1.5$. Even in lower excitation power densities, the observed up-conversion fluorescence was the same $\log (I)-\log (P)$ relationship as in the femtosecond laser excitation. At lower temperatures, the value approached "2", indicating a two photon process accompanying with nonradiative relaxation.

As for up-conversion process of $\mathrm{Er}^{3+}$ fluorescence in $\mathrm{TeO}_{2-}$ $\mathrm{Nb}_{2} \mathrm{O}_{5}-\mathrm{ZnO}$ glass studied, the following three possibilities should be discussed (refer to Fig. 2). These processes are all involved with two photons.

(a) Direct two photon absorption (TPA) process: two photons were simultanesously absorbed and $\mathrm{Er}^{3+}$ ion was excited to higher energy levels, which is normaly observed in a strong excitation condition. Owing to the large spectral width, $\sim 200 \mathrm{~nm}$, of the femto second pulse, some of $\mathrm{Er}^{3+}$ ions can be excited to ${ }^{4} \mathrm{I}_{11 / 2}$ level by one photon while most $\mathrm{Er}^{3+}$ ions are excited to ${ }^{4} \mathrm{I}_{9 / 2}$. Subsequently, direct TPA, if it were in case, would produce $\mathrm{Er}^{3+}$ ions in higher energy levels of ${ }^{2} \mathrm{H}_{9 / 2}$ and ${ }^{4} \mathrm{~F}_{5 / 2,3 / 2}$.

(b) Excited state absorption (ESA) process: one photon was used to excite $\mathrm{Er}^{3+}$ ion to an intermediate level and after non- radiative relaxation to a lower excited level, then another sequential fs pulse excited it to a higher energy level.

(c) Energy transfer (ET) process: two photons excited two neighbouring $\mathrm{Er}^{3+}$ ions, which were interacted each other so that the absorbed energy in one $\mathrm{Er}^{3+}$ ions (A) was transferred to the other $\mathrm{Er}^{3+}$ ion $(\mathrm{B})$, resulting in the excitation to a higher excited level of $\mathrm{Er}^{3+}$ ion (B).

On the other hand, it was found that $\mathrm{Er}^{3+}$ ions in aluminosilicate glass were excited via three photon process, resulting form a laser power dependence $(n=3)$ on green up-conversion intensity (not shown here). This could simply be explained by three photon absorption over a large band-gap energy of the aluminosilicate glass in a similar way as our previous report. ${ }^{6}$ From these observations, it is concluded that direct TPA process by femtosecond 800nm laser pulses is forbidden for $\mathrm{Er}^{3+}$-ions and a higher order phenomenon with three photons then occurs in welldispersed system of $\mathrm{Er}^{3+}$ ions. Hence, the reduction of the $n$ value from 2 in $\mathrm{Er}^{3+}$-doped $\mathrm{TeO}_{2}-\mathrm{Nb}_{2} \mathrm{O}_{5}-\mathrm{ZnO}$ glass will be attributable to absorption saturation of energy donor in ESA of Fig. 1(b) or induced relaxation, such as back transfer, of energy acceptor.

With different repetition ratios of sequential femtosecond laser pulses, the up-conversion fluorescence was estimated, as shown

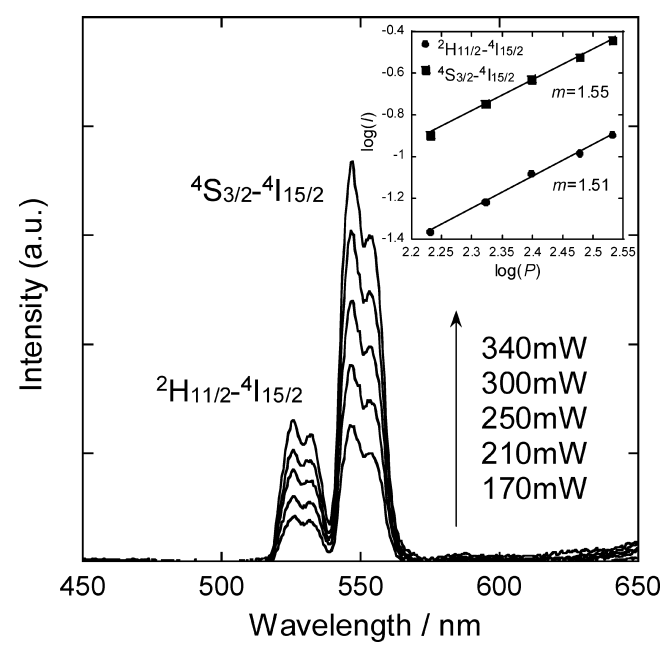

Fig. 1. Up-conversion fluorescence spectra of 1.5 mass $\% \mathrm{Er}_{2} \mathrm{O}_{3}$ doped $76 \mathrm{TeO}_{2} \cdot 20 \mathrm{Nb}_{2} \mathrm{O}_{5} \cdot 4 \mathrm{ZnO}$ glass irradiated with semiconductor laser $(800$ $\mathrm{nm})$.

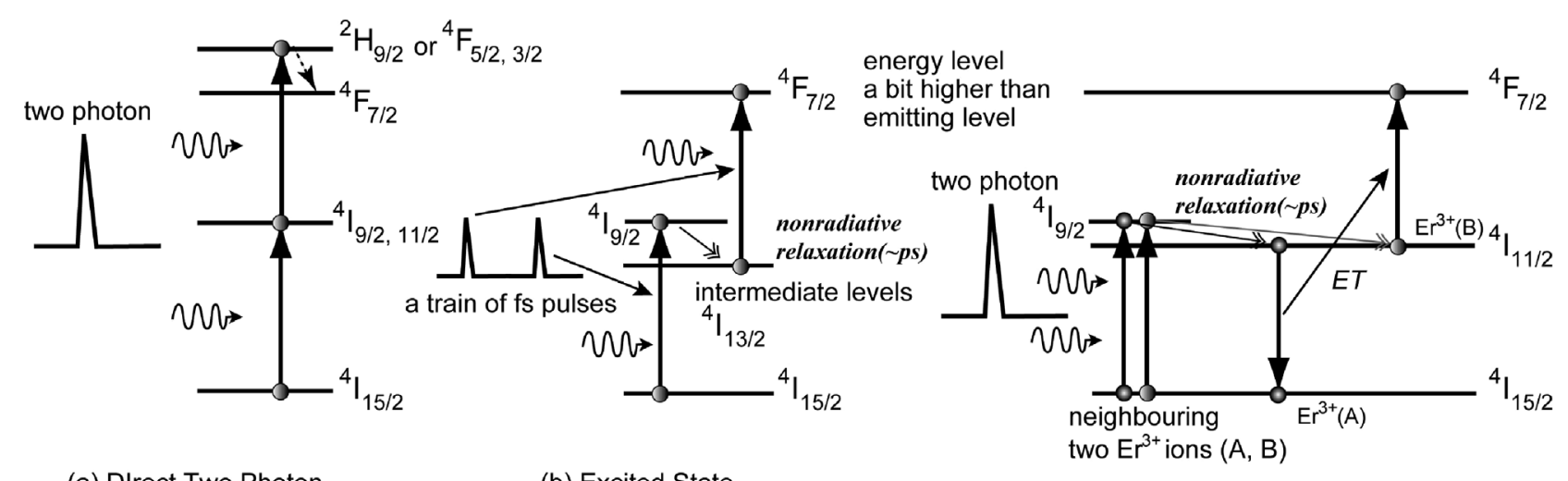

(a) DIrect Two Photon Absorption (TPA)

(b) Excited State Absorption (ESA)

(c) Energy transfer (ET)

Fig. 2. Schematical illustration of possible up-conversion mechanisms for $\mathrm{Er}^{3+}$ ions in $\mathrm{TeO}_{2}-\mathrm{Nb}_{2} \mathrm{O}_{5} \mathrm{ZnO}$ glass. 


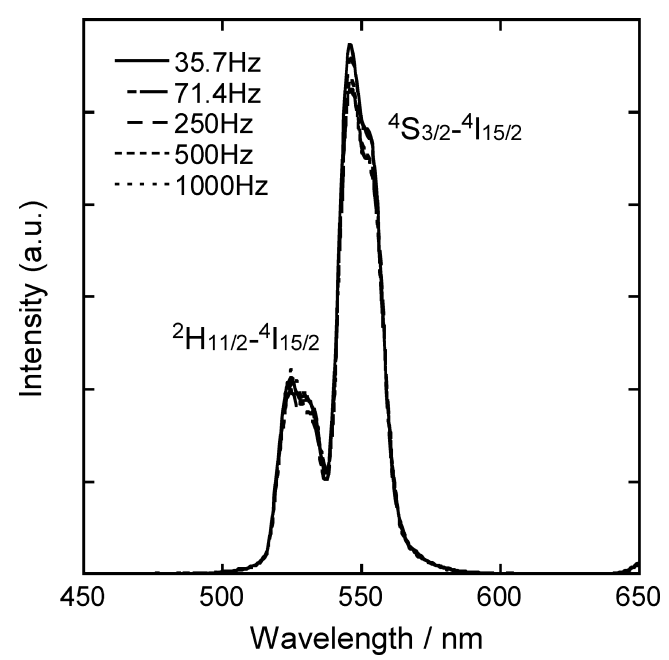

Fig. 3. Up-conversion fluorescence spectra of 1.5 mass $\% \mathrm{Er}_{2} \mathrm{O}_{3}$ doped $76 \mathrm{TeO}_{2} \cdot 20 \mathrm{Nb}_{2} \mathrm{O}_{5} \cdot 4 \mathrm{ZnO}$ glass irradiated with femtosecond laser $(800$ $\mathrm{nm})$.

in Fig. 3. The repetition ratio was changed from $1 \mathrm{kHz}$ down to $35.7 \mathrm{~Hz}$, resulting in no significant change in the green upconversion fluorescence. This means that a train of femtosecond pulses could not be influenced with excited state absorption (ESA), though the lifetimes of intermediate excited states $\left({ }^{4} \mathrm{I}_{9 / 2}\right.$ and ${ }^{4} I_{13 / 2}$ ) were originally in an order of millisecond (see also Table 1). Additionally, we have to remind ourself that one femtosecond pulse is too short to excite $\mathrm{Er}^{3+}$ ions non-radiatively relaxed to an intermediate excited state in its time duration. Thus, it is very meaningful to consider the observed up-conversion fluorescence in terms of energy transfer $(E T)$.

Next, we measured an optical absorption spectrum of $\mathrm{Er}^{3+}$ doped $\mathrm{TeO}_{2}-\mathrm{Nb}_{2} \mathrm{O}_{5}-\mathrm{ZnO}$ glass studied and analyzed it in JuddOfelt theory, ${ }^{7)}$ which allowed us to obtain phehomenogical parameters of $\Omega_{2}, \Omega_{4}, \Omega_{6}$, known as Judd-Ofelt parameters, for the prediction of a lifetime of each excited state of $\mathrm{Er}^{3+}$ ions in this glass. At $8 \mathrm{~K}$, the fluorescence decay curves of ${ }^{4} \mathrm{I}_{9 / 2},{ }^{4} \mathrm{~F}_{9 / 2}$ and ${ }^{4} \mathrm{~S}_{3 / 2}$ emittive level were detected to estimate the experimental values of lifetimes of the corresponding excited levels. The lifetimes of ${ }^{4} \mathrm{I}_{11 / 2}$ and ${ }^{4} \mathrm{I}_{13 / 2}$ were observed in the mesurement of fluorescence decays at $77 \mathrm{~K}$, where each of these lifetimes approached a constant value and so it was found that the temperature was low enough to estimate a radiative transition probability for each of them. Table 1 summaries Judd-Ofelt parameters $\left(\Omega_{2}, \Omega_{4}, \Omega_{6}\right)$ with comparison of those of $\mathrm{Er}^{3+}$-doped $\mathrm{TeO}_{2}-\mathrm{Nb}_{2} \mathrm{O}_{5}-\mathrm{Na}_{2} \mathrm{O}$ glass found in literatures, ${ }^{8)}$ and the experimental and theoretical prediction for the lifetimes. In the obtained Judd-Ofelt parameters, $\Omega_{2}$ and $\Omega_{6}$ were lower than the values calculated for $\mathrm{TeO}_{2}-\mathrm{Nb}_{2} \mathrm{O}_{5}-\mathrm{Na}_{2} \mathrm{O}$ glass, while $\Omega_{4}$ was larger. The predicted lifetimes of the excited state of $\mathrm{Er}^{3+}$ ions doped in these glasses are comparative to those for $\mathrm{TeO}_{2}-\mathrm{Nb}_{2} \mathrm{O}_{5}$ $\mathrm{Na}_{2} \mathrm{O}$ glass doped with $\mathrm{Er}^{3+}$ ions. ${ }^{8}$ Curiously, the experimental values of the lifetimes for ${ }^{4} \mathrm{I}_{9 / 2},{ }^{4} \mathrm{~F}_{9 / 2}$ and ${ }^{4} \mathrm{~S}_{3 / 2}$ levels were all shorter than the predicted values, strongly indicating that $\mathrm{Er}^{3+}$ ions in excited states could be interacted each other and excitation energy transfer processes were not negligible.

As a possible excitation-emission process, we can propose the following mechanism (see also Fig. 4): First, the transition from the ground state ${ }^{4} \mathrm{I}_{15 / 2}$ to ${ }^{4} \mathrm{I}_{9 / 2}$ occurs by the fs pulsed irradiation at $800 \mathrm{~nm}$. High power density of fs laser, of the order of TW/
Table 1. Judd-Ofelt Parameters and Emission Lifetimes of 1.5 mass $\%$ $\mathrm{Er}_{2} \mathrm{O}_{3}$ Doped $76 \mathrm{TeO}_{2} \cdot 20 \mathrm{Nb}_{2} \mathrm{O}_{5} \cdot 4 \mathrm{ZnO}$ Glass

\begin{tabular}{ccccc}
\hline & & \multicolumn{2}{c}{ Judd-Ofelt theory } & \\
\cline { 3 - 4 } & & Our work & Ref. ${ }^{8)}$ & Experiment at $8 \mathrm{~K}$ \\
\hline \multirow{2}{*}{$\left(\times 10_{t}^{-20} \mathrm{~cm}^{2}\right)$} & $\Omega_{2}$ & 6.59 & 6.86 & - \\
& $\Omega_{4}$ & 1.70 & 1.53 & - \\
& $\Omega_{6}$ & 0.967 & 1.12 & - \\
\hline \multirow{4}{*}{$\tau(\mu \mathrm{s})$} & ${ }^{4} \mathrm{~S}_{3 / 2}$ & 304 & 230 & 48 \\
& ${ }^{4} \mathrm{~F}_{9 / 2}$ & 277 & 252 & 59 \\
& ${ }^{4} \mathrm{I}_{9 / 2}$ & 2233 & 2430 & 64 \\
& ${ }^{4} \mathrm{I}_{11 / 2}$ & 2,673 & 2,320 & $283^{*}$ \\
& ${ }^{4} \mathrm{I}_{13 / 2}$ & 4,486 & 3,020 & $2,649^{*}$ \\
\hline
\end{tabular}

Ref. ${ }^{8)}: \mathrm{TeO}_{2}-\mathrm{Nb}_{2} \mathrm{O}_{5}-\mathrm{Na}_{2} \mathrm{O}: \mathrm{Er}^{3+}$ glass, * measured at $77 \mathrm{~K}$.

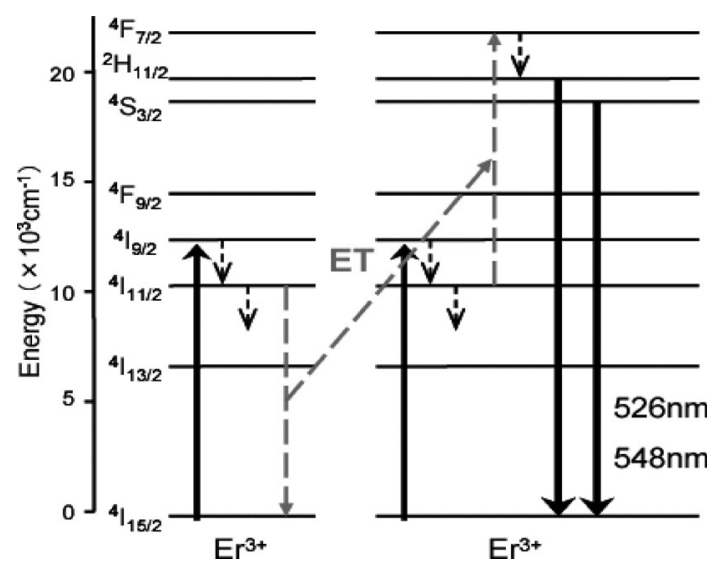

Fig. 4. Energy level diagram of $\mathrm{Er}^{3+}$ and possible transition pathways in 1.5 mass $\% \mathrm{Er}_{2} \mathrm{O}_{3}$ doped $76 \mathrm{TeO}_{2} \cdot 20 \mathrm{Nb}_{2} \mathrm{O}_{5} \cdot 4 \mathrm{ZnO}$ glass.

$\mathrm{cm}^{2}$, gives rise to high population of the excited ${ }^{4} \mathrm{I}_{9 / 2}$ level. After multiphoton relaxation to ${ }^{4} \mathrm{I}_{11 / 2}$, or direct ${ }^{4} \mathrm{I}_{11 / 2}$ pumping by broadband fs pulse, the excitation energy transfer between the excited $\mathrm{Er}^{3+}$ ions in nearest neighbor is possible to occur, eventually to populate one of $\mathrm{Er}^{3+}$ ions to ${ }^{4} \mathrm{~F}_{7 / 2}$ level higher than ${ }^{4} \mathrm{~S}_{3 / 2}$ and ${ }^{2} \mathrm{H}_{11 / 2}$, and the other to the ground state (energy transfer up-conversion $(E T U)) .{ }^{9}$ As a result of the subsequent multiphonon relaxation from ${ }^{4} \mathrm{~F}_{7 / 2}$ to these two levels investigated, the green upconversion fluorescence was observed. Alternative energy transfer process is that via ${ }^{4} \mathrm{I}_{9 / 2}$ level $\left({ }^{4} \mathrm{I}_{9 / 2}+{ }^{4} \mathrm{I}_{9 / 2} \rightarrow{ }^{4} \mathrm{~S}_{3 / 2}+{ }^{4} \mathrm{I}_{13 / 2}\right)$. More or less, this $E T$ process could be involved to the observed upconversion fluorescence of $\mathrm{Er}^{3+}$ ions in $\mathrm{TeO}_{2}-\mathrm{Nb}_{2} \mathrm{O}_{5}-\mathrm{ZnO}$ glass.

Several types of energy transfer process are reported for $\mathrm{Er}^{3+}$ ions. ${ }^{9)}$ In relation with the generation of $\mathrm{Er}^{3+}$ green up-conversion fluorescence, we have noted ${ }^{4} \mathrm{I}_{11 / 2},{ }^{4} \mathrm{I}_{11 / 2} \rightarrow{ }^{4} \mathrm{~F}_{7 / 2},{ }^{4} \mathrm{I}_{15 / 2}$ (ETU1) and ${ }^{4} \mathrm{I}_{9 / 2},{ }^{4} \mathrm{I}_{9 / 2} \rightarrow{ }^{4} \mathrm{~S}_{3 / 2},{ }^{4} \mathrm{I}_{13 / 2}$ (ETU2). As seen in Table 1, one can notice that ${ }^{4} \mathrm{~S}_{3 / 2}$ and ${ }^{4} \mathrm{~F}_{9 / 2}$ levels have much shorter lifetime than given theoretically from Judd-Ofelt analysis. It indicates that the fluorescence from these levels compete with energy transfer process as well. A plausible mechanism for lowering ${ }^{4} \mathrm{~S}_{3 / 2}$ and ${ }^{7} \mathrm{~F}_{9 / 2}$ lifetime is ${ }^{4} \mathrm{~S}_{3 / 2},{ }^{4} \mathrm{I}_{13 / 2} \rightarrow{ }^{4} \mathrm{I}_{9 / 2},{ }^{4} \mathrm{I}_{9 / 2}$, which is a back transfer process of ETU2, and ${ }^{4} \mathrm{~F}_{9 / 2},{ }^{4} \mathrm{~F}_{9 / 2} \rightarrow{ }^{4} \mathrm{~F}_{7 / 2},{ }^{4} \mathrm{I}_{11 / 2}$, respectively. The back transfer of ETU2 can also contribute to the reduction of the $n$ value in the $I-P$ correlation although two photons are used for exciting $\mathrm{Er}^{3+}$ ion to ${ }^{4} \mathrm{~S}_{3 / 2}$ level. As temperature is decreased, the forward ETU2 process has a faster rate because the population 
of ${ }^{4} \mathrm{I}_{9 / 2}$ level is increased and the back transfer process becomes negligible. As a consequence, the value of $n$ approaches " 2 " at lower temperatures.

\section{Conclusion}

In this paper, we discussed excitation-emission mechanisms of green up-conversion fluorescence for $\mathrm{Er}^{3+}$ ions in $\mathrm{TeO}_{2}-\mathrm{Nb}_{2} \mathrm{O}_{5}-$ $\mathrm{ZnO}$ glass under excitation of $800 \mathrm{~nm}$ fs laser. We considered different types of two photon processes, direct two photon absorption (TPA), excited state absorption (ESA), and energy transfer (ET) process between neighbouring $\mathrm{Er}^{3+}$ ions. The plausible explanation was given in the following: First, the transition from the ground state ${ }^{4} I_{15 / 2}$ to ${ }^{4} I_{9 / 2}$ occurred by the fs pulsed irradiation at $800 \mathrm{~nm}$. High power density of fs laser, of the order of $\mathrm{TW} / \mathrm{cm}^{2}$, gave rise to high population of the excited ${ }^{4} \mathrm{I}_{9 / 2}$ level. After multiphonon relaxation to ${ }^{4} \mathrm{I}_{11 / 2}$, the excitation energy transfer between the excited $\mathrm{Er}^{3+}$ ions in nearest neighbor was possible to occur, eventually to populate one of $\mathrm{Er}^{3+}$ ions to ${ }^{4} \mathrm{~F}_{7 / 2}$ level higher than ${ }^{4} \mathrm{~S}_{3 / 2}$ and ${ }^{2} \mathrm{H}_{11 / 2}$, and the other to the ground state (energy transfer up-conversion $(E T U)$ ). As a result of the subsequent multiphonon relaxation from ${ }^{4} \mathrm{~F}_{7 / 2}$ to these two levels investigated, the green up-conversion fluorescence was observed. Additionally, the ET process $\left({ }^{4} \mathrm{I}_{9 / 2}+{ }^{4} \mathrm{I}_{9 / 2} \rightarrow{ }^{4} \mathrm{~S}_{3 / 2}+{ }^{4} \mathrm{I}_{13 / 2}\right)$ could be involved to the observed up-conversion fluorescence of $\mathrm{Er}^{3+}$ ions in $\mathrm{TeO}_{2}-\mathrm{Nb}_{2} \mathrm{O}_{5}-\mathrm{ZnO}$ glass.
Acknoledgements T. H. would like to thank Professor Philippe Thomas of Limoges University, Dr. Masahide Takahashi, and Professor Setsuhisa Tanabe of Kyoto University for their fruitful discussions and suggestions. This research was supported by a Grantin-Aid for Scientific Research (No. 18685022 and No. 19018011) from the Ministry of Education, Science, and Culture of Japan.

\section{References}

1) T. Komatsu, H. Tawarayama and H. Mori, J. Non-Cryst. Solids, 135, 105-113 (1991)

2) T. Hayakawa, M. Hayakawa and M. Nogami, J. Alloy and Сотр., 451, 77-80 (2008).

3) T. Hayakawa, M. Hayakawa and M. Nogami, International Conference on f-elements 2006 (ICfe06), 2006, p. B-354-O.

4) J. Lin, W. Huang, Z. Sun, C. S. Ray and D. E. Day, J. NonCryst. Solids, 336, 189-194 (2004).

5) K. Arai, H. Namikawa, K. Kumata, T. Honda, Y. Ishii and T. Handa, J. Appl. Phys., 59, 3430-3436 (1986).

6) H. You, T. Hayakawa and M. Nogami, Appl. Phys. Lett., 85, 3432-3434 (2004).

7) B. R. Judd, Phys. Rev., 127, 750-761 (1962); G. S. Ofelt, J. Chem. Phys., 37, 511-520 (1962).

8) H. Lin, S. Jiang, J. Wu, F. Song, N. Peyghambarian and E. Y. B. Pun, J. Phys D: Appl. Phys., 36, 812-817 (2003).

9) A. Kanoun, N. Jaba and A. Brenier, Opt. Mater., 26, 79-83 (2004). 